\title{
COPD prevalence and the differences between newly and previously diagnosed COPD patients in a spirometry program
}

\author{
*Markos Minasa, Chrisi Hatzogloua, Eleni Karetsia, Andriana I Papaioannou ${ }^{a}$, Kalliopi Tanou, \\ Rita Tsarouchaa, Eudoxia Gogou ${ }^{a}$, Konstantinos I Gourgoulianisa, Konstantinos Kostikas ${ }^{a}$
}

a Respiratory Medicine Department, University of Thessaly Medical School, University Hospital of Larissa, Greece

Originally submitted 28th May 2009; resubmitted 24th July 2009; revised version received 6th December 2009;

final revised version received 2nd March 2010; accepted 6th April 2010; online 7th June 2010

\begin{abstract}
Aims: To evaluate the prevalence and severity of COPD in a primary care population participating in a spirometry program. Differences between newly and previously diagnosed COPD patients were identified.

Methods: A spirometry program was conducted in 15 primary care centres. Visitors aged over 30 years who were willing to perform spirometry were included in this program.

Results: A total of 1,526 subjects provided acceptable spirometries. COPD prevalence in our population was $18.4 \%$, of whom $69.0 \%$ were newly diagnosed. Most patients were classified as GOLD stages I and II ( $26.0 \%$ and $54.0 \%$, respectively). COPD diagnosis was related to gender (men), age (older subjects), history of repeated respiratory infection in childhood, smoking (>10 pack-years) and presence of symptoms (cough, dyspnoea, wheezing). Variables related to newly diagnosed COPD were younger age and absence of chronic cough.

Conclusions: A primary care spirometry program may identify a large proportion of undiagnosed COPD patients especially in the early stages of the disease. Newly diagnosed COPD patients were of younger age and presented with less symptoms. These results support the need for spirometry programs in primary care for early COPD detection.

(C) 2010 Primary Care Respiratory Society UK. All rights reserved.

M Minas et al. Prim Care Resp J 2010; 19(4): 363-370

doi:10.4104/pcrj.2010.00034
\end{abstract}

Keywords Chronic obstructive pulmonary disease, early diagnosis, prevalence, primary health care, screening, spirometry

The full version of this paper, with online Appendix,

is available at www.thepcrj.org

\section{Introduction}

Chronic obstructive pulmonary disease (COPD) is characterised by airflow limitation that is not fully reversible. The development of COPD depends on the patient's exposure to noxious particles or gases, the most important being tobacco smoke. ${ }^{1}$ The symptoms of the disease are mainly cough, sputum production and dyspnoea. Chronic cough and sputum production may precede the development of airflow limitation for years, yet significant airflow obstruction may develop without cough and sputum production. ${ }^{1}$ Therefore, COPD remains largely underdiagnosed and underperceived. ${ }^{2}$

Early diagnosis of COPD is important, especially in current smokers, since smoking cessation is the only intervention which delays the rate of decline in lung function. ${ }^{3}$ Although early diagnosis of COPD does not lead directly to a delay in the rate of decline in lung function, there is evidence that smokers with COPD quit smoking more often. ${ }^{4,5} \mathrm{~A}$ previous study tried to identify the successful factors in quitting smoking between smokers with and without airflow limitation; the results indicated that the predictors of success in quitting smoking were older age, a smaller pack-year history of tobacco smoking, and poorer lung function. ${ }^{6}$

The diagnosis of COPD requires a high suspicion for

\footnotetext{
* Corresponding author: Dr Markos Minas, Respiratory Medicine Department, University of Thessaly Medical School, University Hospital of Larissa, Larissa, 41110, Greece. Tel: +302413502896 Fax:+302410670240 E-mail:markosminas@hotmail.com
} 
identifying subjects at risk, combined with implementation of good quality spirometry that is necessary for the detection of airflow limitation, the appropriate classification of patients, and which is mandatory for treatment decisions. ${ }^{1}$ Early implementation of spirometry for subjects at risk may identify the disease in the early stages. ${ }^{7}$ Both screening and case finding studies have addressed the question of COPD prevalence, with different results. ${ }^{7-10}$ Recently, the BOLD study estimated that the overall prevalence of COPD at stage II or higher was $10.1 \%$ with significant variation between countries. ${ }^{11}$ In Greece, Tzanakis et al. estimated a COPD prevalence of $8.4 \%$, reaching $15.1 \%$ in men in rural areas. ${ }^{12}$ Despite the growing body of evidence suggesting that early intervention may affect the clinical manifestations of COPD, ${ }^{13}$ COPD is generally not diagnosed in its early stages. Reasons for this include the limited use of spirometry in primary care ${ }^{1,14-16}$ along with nihilistic personal views and failure in communication between patients and doctors. ${ }^{17}$ Therefore, identifying the characteristics of newly diagnosed COPD patients in primary care may help in the early diagnosis of COPD.

The aims of the present study included the evaluation of the prevalence and severity of COPD in a population attending primary care offices for a spirometry program, and the identification of differences between newly and previously diagnosed patients with COPD.

\section{Methods}

The study was conducted in 15 primary health care centres in Thessaly, Greece, during an 18-month period (January 2006 to June 2007). All subjects were over 30 years of age, resided near a primary health care practice, and were able and willing to participate in a spirometry program. The program took place in the first week of each month, when study co-ordinators visited the primary care practices. Public invitation to participate in the spirometry program with local advertising preceded the spirometry program in each health centre. Subjects were excluded from participation if they had a history of upper or lower respiratory tract infection during the previous four weeks or were unable to perform spirometry. The study was approved by the Ethics Committee of the University Hospital of Larissa and all subjects provided written informed consent.

\section{Study design}

A study questionnaire was completed upon arrival for all subjects, who were subsequently submitted to physical examination. Body mass index (BMI) and pre- and post-bronchodilation spirometry were assessed. BMI was calculated as the body weight divided by the square of height (expressed in $\mathrm{kg} / \mathrm{m}^{2}$ ).

\section{Study questionnaire}

The study questionnaire (see Appendix 1, available online at www.thepcrj.org) included questions about smoking habits, occupational exposure, history of common respiratory infections, and chronic respiratory symptoms (i.e. cough, sputum production, wheezing and dyspnoea). Subjects with a history of $>100$ cigarettes smoked during their lifetime were considered as smokers, whereas ex-smokers were smokers who had quit smoking for at least 12 months. ${ }^{12,18}$ Smoking status was measured by pack-years (PYS), defined as the number of cigarettes smoked per day divided by 20 and multiplied by the number of years of smoking. According to their smoking history, subjects were classified into five categories: never-smokers; ex-smokers with $<10$ PYS; ex-smokers with > 10 PYS; current smokers with $<10$ PYS; and current smokers with $>10$ PYS. The cut-off limit of 10 PYS was chosen in accordance with previous epidemiologic studies. ${ }^{11}$

\section{Spirometry}

Spirometry was performed with a dry spirometer (KoKo Legend, Ferraris, UK), according to American Thoracic Society (ATS) recommendations. ${ }^{19}$ Calibration checks were performed every morning, 30 minutes before the beginning of the spirometry program. Spirometry testing was performed by physicians who had undergone a special training program by two pneumonologists. Forced expiratory manoeuvres were repeated until three reproducible acceptable tests were obtained and the best forced expiratory volume in one second $\left(F E V_{1}\right)$, forced vital capacity (FVC), and $\mathrm{FEV}_{1} / \mathrm{FVC}$ ratio, were recorded. ${ }^{19} \mathrm{~A}$ bronchodilator reversibility test using $400 \mathrm{mcg}$ of salbutamol.was performed in all patients with obstructive spirometry. Obstructive spirometry was defined as an $\mathrm{FEV}_{1} / \mathrm{FVC}$ ratio $<0.7$ in accordance with GOLD guidelines.' An increase in $\mathrm{FEV}_{1}>12 \%$ and $>200 \mathrm{ml}$ from baseline was considered significant. ${ }^{20}$ Patients who had used their regular long-acting bronchodilators in the morning prior to spirometry were included in the study, and their spirometric values were considered as post-bronchodilation since all spirometries were performed in the morning. Patients who had received only short-acting bronchodilators followed the above-mentioned bronchodilation protocol.

\section{Diagnosis of COPD}

After completion of the study questionnaire, all participants were evaluated by experienced chest physicians ( $\mathrm{KK}, \mathrm{CH}, \mathrm{KIG})$, who established the diagnosis of COPD. COPD diagnosis was based on the global assessment of patients, including a history of exposure to noxious particles or gases (especially smoking, but also occupational dusts and indoor air pollution), compatible symptoms (e.g. cough, sputum production, dyspnoea), and an obstructive spirometry pattern (post-bronchodilator $\mathrm{FEV}_{1} / \mathrm{FVC}$ ratio <0.7). ${ }^{1}$ Classification of COPD was based on postbronchodilator $\mathrm{FEV}_{1}$, according to GOLD guidelines (Stage I - mild COPD, FEV $1 \geq 80.0 \%$ predicted; Stage $\|$ - moderate COPD, $50.0 \% \leq \mathrm{FEV}_{1}<80.0 \%$ predicted; Stage III - severe COPD, $30.0 \% \leq \mathrm{FEV} 1<50.0 \%$; Stage IV - very severe COPD, 30.0\% $\leq \mathrm{FEV}$ 1 or $\mathrm{FEV}_{1}<50.0 \%$ predicted with respiratory failure). ${ }^{1}$

A previous diagnosis of COPD was based on patients' medical 
records and drugs received, as well as previous spirometries, whenever possible. All patients with a previous diagnosis of COPD were thoroughly evaluated by the study physicians and current spirometry was used for the confirmation of the diagnosis and the classification of the patient according to GOLD stages.

In terms of the differentiation between COPD and asthma, asthma diagnosis was based on pre-defined criteria, as previously described in a similar population - i.e. briefly, the presence of a long standing history of asthma-like symptoms from childhood or adolescence, along with seasonal distribution and a history of atopy, and the presence of significant reversibility of airway obstruction on spirometry. ${ }^{21}$ Again, the final diagnosis was based on the global clinical evaluation by the study physicians. Patients with asthma were included in the analysis as non-COPD patients.

\section{Statistical analysis}

Demographic data are presented as mean \pm standard deviation (SD), with the exception of spirometric values which are presented as median (interquartile range). Comparisons of proportions were performed using chi-square tests, whereas differences in numerical variables between groups were performed with unpaired t-tests or Mann-Whitney U-tests for normally and skewed data, respectively.

For the evaluation of variables related to the diagnosis of COPD, sex, age, BMI, occupational exposure, frequency of respiratory infections, smoking habit (PYS), cough, sputum production, wheezing and dyspnoea were included as
Figure 1. Flow chart of study participants.

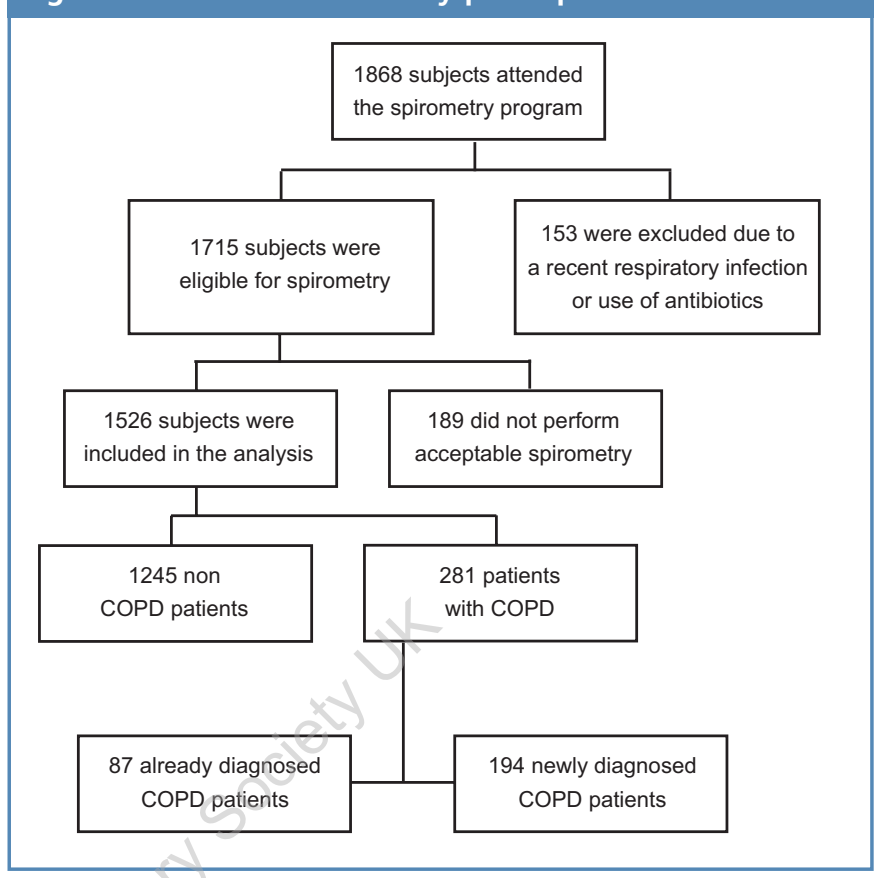

independent variables in univariate and multivariate analyses, with the diagnosis of COPD being the dependent variable. The variable PYS was included as a categorical variable, according to the predefined classification. Univariate analyses were performed using binary logistic regression analysis whereas multivariate

Table 1. Patient's characteristics.

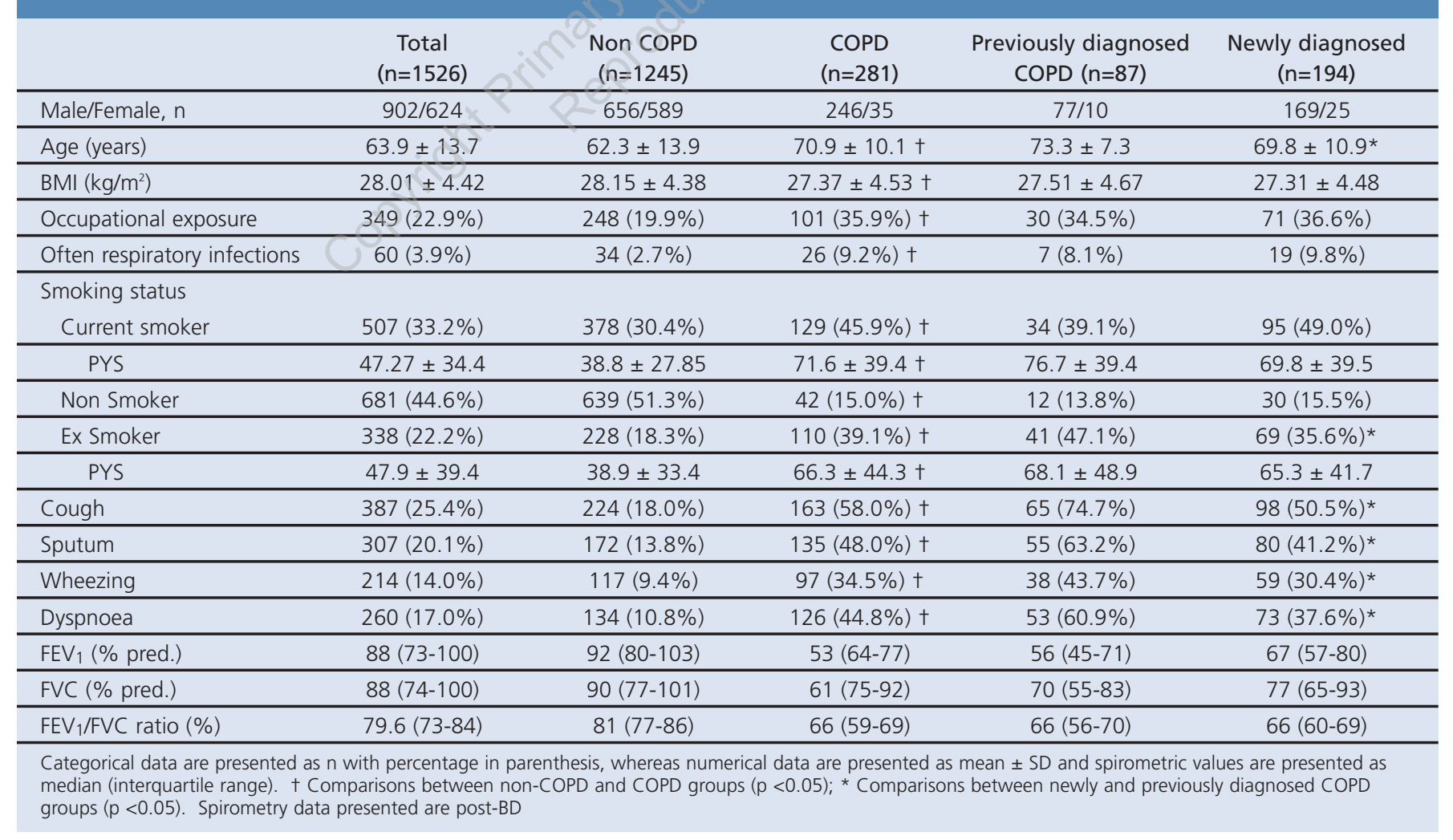


analyses were performed using forward stepwise binary logistic regression analysis. The same dependent variables were analysed in a similar way in order to identify variables related to newly diagnosed COPD. Data were analysed using SPSS 15.0 for Windows (SPSS Co, Chicago, IL, USA). P-values $<0.05$ were considered statistically significant.

\section{Results}

The flow chart of the study subjects is presented in Figure 1. In the spirometry program 1,868 patients were examined of whom $1,715(91.8 \%)$ were eligible for spirometry. Among the 1,715 participants, 1,526 subjects (88.9\%) provided an acceptable spirometry and were included in the analysis. Asthma was diagnosed in 218 subjects (14.2\%). The demographics of the 1,526 subjects included are presented in Table 1.

COPD was diagnosed in 281 of the 1526 subjects providing an overall COPD prevalence of $18.4 \%$ in our population. Newly diagnosed COPD patients $(n=194)$ represented $69.0 \%$ of the COPD patients. Table 2 shows the distribution of patients according to disease severity and sex. Interestingly, $73.7 \%$ of the COPD patients belonged to COPD stages II or higher. Of these patients, $65.7 \%$ were newly diagnosed. According to our data, $75.6 \%$ of patients in stages I and II respectively are newly diagnosed (Table 2). There were 35 women (12.5\%)
Table 2. Distribution of COPD patients according to GOLD COPD stages and by sex.

\begin{tabular}{crrr} 
& $\begin{array}{c}\text { COPD } \\
(\mathrm{n}=281)\end{array}$ & $\begin{array}{c}\text { COPD old } \\
(\mathrm{n}=87)\end{array}$ & \multicolumn{1}{c}{$\begin{array}{c}\text { COPD new } \\
(\mathrm{n}=194)\end{array}$} \\
\hline Stage I & $74(26.3 \%)$ & $16(18.4 \%)$ & $58(29.9 \%)$ \\
\hline Men/Women & $60 / 14$ & $14 / 2$ & $46 / 12$ \\
\hline Stage II & $152(54.1 \%)$ & $39(44.8 \%)$ & $113(58.3 \%)$ \\
\hline Men/Women & $136 / 16$ & $34 / 5$ & $102 / 11$ \\
\hline Stage III & $53(18.9 \%)$ & $30(34.5 \%)$ & $23(11.8 \%)$ \\
\hline Men/Women & $48 / 5$ & $27 / 3$ & $21 / 2$ \\
\hline Stage IV & $2(0.7 \%)$ & $2(2.3 \%)$ & $0(0 \%)$ \\
\hline Men/Women & $2 / 0$ & $2 / 0$ & $0 / 0$ \\
\hline
\end{tabular}

Data are presented as actual numbers with percentages in every

subgroup in parenthesis.

among the 281 COPD patients. The vast majority of women with COPD (25 out of 35) were newly diagnosed. Of these, $92 \%$ were classified as COPD stages I and II (Table 2).

\section{Differences between COPD and non-COPD patients}

COPD patients were more often male, older in age, and had a lower BMI compared to subjects without COPD. COPD patients were also more often smokers (current and ex-smokers), with a higher smoking habit. All respiratory symptoms were more often present in COPD patients (Table 1).

Table 3. Univariate and multivariate analysis.

\begin{tabular}{|c|c|c|c|c|c|c|}
\hline \multirow[t]{2}{*}{ Variables } & \multicolumn{3}{|c|}{ Univariate analysis } & \multicolumn{3}{|c|}{ Multivariate analysis } \\
\hline & OR & $95 \% \mathrm{Cl}$ & $P$ value & OR & $95 \% \mathrm{Cl}$ & $P$ value \\
\hline \multicolumn{7}{|c|}{ Comparison between COPD and non-COPD patients } \\
\hline Male Sex & 6.27 & $4.32-9.09$ & $<0.001$ & 2.27 & $1.42-3.62$ & 0.001 \\
\hline Age & 1.06 & $1.04-1.07$ & $<0.001$ & 1.06 & $1.05-1.07$ & $<0.001$ \\
\hline $\mathrm{BMI}$ & 0.96 & $0.93-0.99$ & 0.008 & & & \\
\hline Occupational exposure & 2.26 & $1.70-2.99$ & $<0.001$ & & & \\
\hline Often respiratory infections during childhood & 3.63 & $2.14-6.16$ & $<0.001$ & 2.93 & $1.48-5.77$ & $<0.001$ \\
\hline PYS & 1.46 & $1.35-1.58$ & $<0.001$ & 1.41 & $1.25-1.59$ & $<0.001$ \\
\hline Cough & 6.30 & $4.77-8.32$ & $<0.001$ & 2.48 & $1.7-3.6$ & $<0.001$ \\
\hline Sputum & 5.77 & $4.34-7.66$ & $<0.001$ & & & \\
\hline Wheezing & 5.08 & $3.72-6.94$ & $<0.001$ & 1.52 & $1.01-2.32$ & $<0.05$ \\
\hline Dyspnoea & 6.74 & $5.01-9.06$ & $<0.001$ & 2.4 & $1.64-3.52$ & $<0.001$ \\
\hline \multicolumn{7}{|c|}{ Comparison between newly and previously diagnosed COPD patients } \\
\hline Male Sex & 0.87 & $0.40-1.89$ & ns & & & \\
\hline Age & 0.96 & $0.94-0.99$ & 0.007 & 0.96 & $0.93-0.99$ & 0.004 \\
\hline BMI & 0.99 & $0.94-1.05$ & ns & & & \\
\hline Occupational exposure & 1.01 & $0.65-1.86$ & ns & & & \\
\hline Often respiratory infections during childhood & 1.24 & $0.50-3.07$ & ns & & & \\
\hline PYS & 1.08 & $0.91-1.29$ & ns & & & \\
\hline Cough & 0.35 & $0.20-0.60$ & $<0.001$ & 0.35 & $0.20-0.62$ & $<0.001$ \\
\hline Sputum & 0.41 & $0.24-0.69$ & 0.001 & & & \\
\hline Wheezing & 0.56 & $0.33-0.95$ & 0.031 & & & \\
\hline Dyspnoea & 0.39 & $0.23-0.65$ & $<0.001$ & & & \\
\hline
\end{tabular}




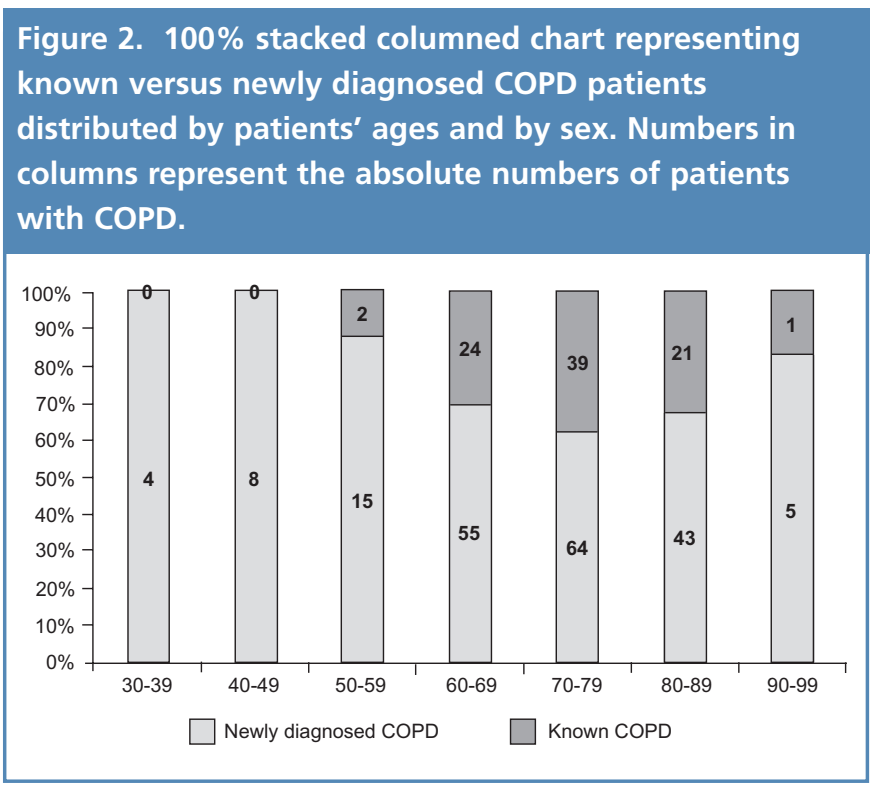

Univariate and multivariate analyses are shown in Table 3. In univariate analysis, the comparison between COPD patients and non-COPD patients showed that all factors examined are related to the presence of COPD. In multivariate analysis, male sex $(p=0.001)$, older age $(p<0.001)$, frequent respiratory infections in childhood $(p<0.001)$, a smoking habit of more than 10 PYS $(p<0.001)$, and the presence of respiratory symptoms $(p<0.001)$ were the most significant factors related to the presence of COPD. The most important factor was the history of frequent respiratory infections during childhood, followed by the presence of cough and dyspnoea.

Age distribution of newly diagnosed COPD patients

Figure 2 shows the distribution of newly diagnosed versus known COPD patients based on their age. Patients between 30 and 50 years old were all newly diagnosed, whereas the percentage of newly diagnosed COPD patients decreases as age increases until the age group 70-79 years. Interestingly, in the two last age groups, the percentage of newly diagnosed COPD patients increases again, providing a U-shaped distribution of newly diagnosed COPD patients (Figure 2). Comparison of the proportions of newly diagnosed COPD patients between age groups showed that these differences were statistically significant $(p<0.001)$. However, at all ages the percentage of newly diagnosed COPD patients remained over $60.0 \%$ in this population (Figure 2).

\section{Differences between newly and previously diagnosed COPD}

Differences are presented in Table 1. Newly diagnosed COPD patients were younger and had less frequent respiratory symptoms (cough, sputum, wheezing and dyspnoea) compared to previously diagnosed COPD patients (Table 1). They had a smaller number of pack-years smoking history than already diagnosed COPD patients, for both the current and ex- smokers group, but this difference did not reach statistical significance. However, diagnosed COPD patients had a higher percentage of ex-smokers.

In the univariate analysis, the variables that were related to newly diagnosed COPD in the spirometry program were younger age $(p=0.007)$ and less frequent presence of all respiratory symptoms (cough, sputum, wheezing and dyspnoea, $\mathrm{p}<0.05)$. In the multivariate analysis, only younger age $(p=0.004)$ and less frequent presence of chronic cough $(p<0.001)$ remained significant predictors of newly diagnosed COPD (Table 3).

\section{Discussion}

In this study we have shown that a significant proportion of patients with COPD can be diagnosed by the implementation of a spirometry program in primary care. We have additionally shown that $69 \%$ of patients with COPD were newly diagnosed and that $88.2 \%$ of newly diagnosed patients were classified as GOLD stages I and II, providing a possible target for early intervention. Spirometry programs should be implemented in primary care for the identification of patients with COPD, since newly diagnosed patients with COPD were of younger age and presented with fewer symptoms.

The overall prevalence of COPD in our population is $18.4 \%$ and these patients were mainly classified as GOLD stages I and II $(26.0 \%$ and $54.0 \%$, respectively). These percentages are similar to those estimated by Shahab et al. from a crosssectional household survey in England, ${ }^{22}$ and by Bednarek et al. who investigated the burden of COPD in a single primary care practice in Poland, ${ }^{23}$ despite the fact that our population differs significantly from those two studies. Several case finding studies in smokers have shown a higher prevalence of COPD., ${ }^{7,24}$ These differences can be attributed to differences between study populations. Our study included eligible subjects attending primary care offices for any reason after public invitation through local advertising, so it does not fulfil the criteria for a screening study. However, our data further support the under-diagnosis of COPD in primary care settings that has been highlighted in previous studies.

Previous data from our group have shown that primary care physicians underdiagnose and undertreat COPD, ${ }^{25,26}$ which may reflect the limited access to spirometry and to specialist pneumonologists in rural areas of Greece. The underdiagnosis of COPD remains a problem in several countries, and several studies have highlighted the importance of spirometry for the identification of obstructive lung disease in primary care. ${ }^{27}$ The current evidence that spirometry is underused by primary care physicians, ${ }^{16,28}$ combined with the fact that the development of screening questionnaires is not yet satisfactory, ${ }^{29}$ has led to the suggestion that the problem of COPD underdiagnosis in primary care may be addressed by the provision of good quality 
spirometry in the primary care setting ${ }^{30-32}-$ as is the case in our study. The implementation of current recommendations on spirometry standards in primary care may also lead to an improvement in the diagnosis of COPD..$^{33}$ Moreover, the implementation of guidelines from the International Primary Care Respiratory Group (IPCRG) $)^{34}$ may further help primary health care physicians raise the standards of health care provided for patients with COPD.

Recent guidelines from the American College of Physicians recommend against spirometry screening in asymptomatic individuals. ${ }^{35}$ However, several studies have revealed a high prevalence of COPD among smokers and ex-smokers with minimal symptoms or no symptoms at all. In a case finding study, Vandervoorde et al. reported high proportions of undiagnosed patients with COPD in the early stages of the disease. ${ }^{24}$ In that study, factors independently associated with newly diagnosed COPD were younger age and less reporting of chronic cough and fatigue. ${ }^{24}$ In a screening study from Sweden only $21 \%$ of patients with mild COPD had symptoms. ${ }^{18}$ Interestingly, data from the European Community Respiratory Health Survey have shown that a considerable percentage of young adults aged 24-44 years old suffer from COPD. ${ }^{36}$ The fact that patients with newly diagnosed COPD in our study were younger and less symptomatic further supports the need for spirometry programs that will identify patients in the early stages of the disease.

The importance of early diagnosis of COPD is supported from studies suggesting that a diagnosis of COPD may improve smoking cessation rates in intervention programs. ${ }^{4}$ Recent data from the UK have additionally shown that spirometry results provided in the form of "lung age" (defined as the age of the average healthy individual who would perform spirometry similarly to the patient) significantly increased the rates of smoking cessation. ${ }^{37}$ Moreover, the treatment of patients with moderate COPD with a Clong-acting anticholinergic bronchodilator may reduce the rate of decline of $\mathrm{FEV}_{1} .^{38}$ This evidence, along with the limited effect of treatment options on the natural history of advanced COPD, suggest that the identification of patients in the early stages of the disease may represent the best intervention in terms of long-term outcomes for these patients.

Another important finding from our study is that the diagnosis of COPD was associated with a history of frequent respiratory infections in childhood. The presence of this factor may involve a significant recollection bias. However, recent data indicate that frequent respiratory infections in childhood were associated with lower $\mathrm{FEV}_{1}$ in adult life. ${ }^{39}$ Moreover, there is accumulating evidence connecting genetic susceptibility and early life events - including antenatal influences on lung growth and frequent respiratory infections in childhood - with the risk of future development of COPD. ${ }^{40}$ This finding is consistent with the results of the present study, where patients with COPD report frequent respiratory tract infections three times more often compared to patients without COPD.

Interestingly, in our study the percentage of women with COPD was only $12.5 \%$. The BOLD study estimated that the prevalence of COPD in women was $8.5 \%$, with significant variations between different areas." The low percentage of women with COPD in our study is probably related to the low smoking habit of Greek women in rural areas. It has recently been shown that $96 \%$ of women above the age of 60 in northern Greece were non-smokers. ${ }^{41}$ Additionally, it is likely that more smokers and especially those with respiratory symptoms may have attended the spirometry program, and this may further account for the lower number of female participants in our study.

We chose to include both smokers and non-smokers in our study for the following reasons. Firstly, we wanted our population to be representative of the general population attending primary care offices. Secondly, recent studies have shown that passive smoking, ${ }^{42}$ as well as indoor and outdoor air pollution, occupational hazards, and infections, ${ }^{43}$ are also important. Finally, an analysis of the BOLD study revealed a significant proportion of never-smokers with COPD. ${ }^{44}$ Bednarek et al. have also shown that $50 \%$ of women with COPD in their population had never smoked. ${ }^{23}$

A significant limitation of our study lies in the subject selection based on local advertising and targeting of the population attending primary care centres. This may have influenced the reported prevalence of COPD in our population, primarily due to the fact that current smokers and subjects with respiratory symptoms were more likely to attend the program. This may further account for the higher number of male participants, since they represent the vast proportion of smokers in rural areas of Greece. However, we followed this approach in order to increase the likelihood for participation in the spirometry program. Another limitation is that the diagnosis of COPD in our study was based on the GOLD criteria that use an $\mathrm{FEV}_{1} / \mathrm{FVC}$ ratio $<0.70$ to define airway obstruction. ' Several authors have recommended the use of the lower limit of normal (LLN), ${ }^{45,46}$ since the $F E V_{1} / F V C$ ratio decreases with increasing age and thus the use of a fixed ratio may lead to misclassification. ${ }^{47}$ However, Mannino et al. have shown that the use of the 0.7 fixed ratio can identify patients at increased risk of death or hospitalisation, even among older adults. ${ }^{48}$ Based on the aforementioned studies and the fact that we wanted our results to be more easily applicable in clinical practice, we chose to use the fixed ratio of 0.70 for the diagnosis of COPD.

\section{Conclusion}

Our data suggest that an invitation strategy for patients to undergo spirometry in primary care offices may identify a 


\section{Summary box}

Underdiagnosis of COPD in primary care remains a significant problem in Greece. Current and ex-smokers with respiratory symptoms should have access to spirometry and should be evaluated for the presence of COPD. The implementation of a spirometry program in primary care may be useful for the identification of COPD patients in the early stages of the disease. Undiagnosed patients with COPD are younger and have less symptoms, especially cough. The most costeffective strategy for eliminating the problem of COPD underdiagnosis remains to be determined.

large proportion of patients with undiagnosed COPD, therefore contributing to the early diagnosis of COPD. The fact that the majority of diagnosed patients had mild-tomoderate COPD, and that newly diagnosed COPD patients in this program were younger and less symptomatic than COPD patients who were already diagnosed, further supports the need for spirometry programs in primary care for the early detection of COPD.

\section{Acknowledgements}

The authors wish to thank the following doctors for their active participation in the spirometry program: Georgios Batavanis, Theodora Kerenidi, Maria Kouri, Stauroula Toukmatzi, Foteini Karachaliou, Eleni Apostolidou, Konstantinos Bartziokas, Christos Daenas, Eleftherios Dalaveris, Anastasia Dimitriou, Alexandra Katsabeki-Katsafli, Agela Koutsokera, Vassiliki Kouloumenta, Foteini Malli, Vassiliki Merenditi, Parthena Mystridou, Melpomeni Ntalapasxa, Maria Papala, Christos Terzoudis, Vassiliki Tsolaki, Pasxalina Tsopa, loanna Verou, Despoina Xynou.

Additionally, they wish to thank Ms. Eleni Souloukou and Ms. Anna Toutoudaki for secretarial support throughout the study.

\section{Conflict of interest declaration}

None of the authors presents any conflicts of interest related to this manuscript.

\section{References}

1. Rabe KF, Hurd S, Anzueto A, et al. Global strategy for the diagnosis, management, and prevention of chronic obstructive pulmonary disease: GOLD executive summary. Am J Respir Crit Care Med 2007;176(6):532-55. http://dx.doi.org/10.1164/rccm.200703-456so

2. Celli BR. Chronic obstructive pulmonary disease: from unjustified nihilism to evidence-based optimism. Proc Am Thorac Soc 2006;3(1):58-65. http://dx.doi.org/10.1513/pats.200510-111JH

3. Scanlon PD, Connett JE, Waller LA, Altose MD, Bailey WC, Buist AS. Smoking cessation and lung function in mild-to-moderate chronic obstructive pulmonary disease. The Lung Health Study. Am J Respir Crit Care Med 2000;161(2 Pt 1):381-90

4. Bednarek M, Gorecka D, Wielgomas J, et al. Smokers with airway obstruction are more likely to quit smoking. Thorax 2006;61(10):869-73. http://dx.doi.org/10.1136/thx.2006.059071

5. Stratelis G, Molstad S, Jakobsson P, Zetterstrom O. The impact of repeated spirometry and smoking cessation advice on smokers with mild COPD. Scand J Prim Health Care 2006;24(3):133-9. http://dx.doi.org/10.1080/ 02813430600819751

6. Gorecka D, Bednarek M, Nowinski A, Puscinska E, Goljan-Geremek A, Zielinski
J. Diagnosis of airflow limitation combined with smoking cessation advice increases stop-smoking rate. Chest 2003;123(6):1916-23. http://dx.doi.org/10.1378/chest.123.6.1916

7. Stratelis G, Jakobsson P, Molstad S, Zetterstrom O. Early detection of COPD in primary care: screening by invitation of smokers aged 40 to 55 years. Br $J$ Gen Pract 2004;54(500):201-06.

8. Lundback B, Lindberg A, Lindstrom $M$, et al. Not 15 but $50 \%$ of smokers develop COPD?--Report from the Obstructive Lung Disease in Northern Sweden Studies. Respir Med 2003;97(2):115-22. http://dx.doi.org/10.1053/ rmed.2003.1446

9. Zielinski J, Czajkowska-Malinowska M, Sankowski Z, et al. [Early detection of COPD by high risk population spirometric screening]. Pneumonol Alergol Pol 2000;68(5-6):217-25.

10. Van Schayck CP, Loozen JM, Wagena E, Akkermans RP, Wesseling GJ. Detecting patients at a high risk of developing chronic obstructive pulmonary disease in general practice: cross sectional case finding study. $B M J$ 2002;324(7350):1370. http://dx.doi.org/10.1136/bmj.324.7350.1370

11. Buist AS, McBurnie MA, Vollmer WM, et al. International variation in the prevalence of COPD (the BOLD Study): a population-based prevalence study. Lancet 2007;370(9589):741-50. http://dx.doi.org/10.1016/S0140-6736 (07)61377-4

12. Tzanakis N, Anagnostopoulou U, Filaditaki V, Christaki P, Siafakas N. Prevalence of COPD in Greece. Chest 2004;125(3):892-900. http://dx.doi.org/ 10.1378/chest.125.3.892

13. Decramer $M$, Rennard $S$, Troosters $T$, et al. COPD as a lung disease with systemic consequences--clinical impact, mechanisms, and potential for early intervention. COPD 2008;5(4):235-56. http://dx.doi.org/10.1080/ 15412550802237531

14. Voelkel NF. Raising awareness of COPD in primary care. Chest 2000;117(5 Suppl 2):372S-5S. http://dx.doi.org/10.1378/chest.117.5_suppl_2.372S

15. Caramori G, Bettoncelli $G$, Tosatto $R$, et al. Underuse of spirometry by general practitioners for the diagnosis of COPD in Italy. Monaldi Arch Chest Dis 2005;63(1):6-12.

16. Lusuardi M, De Benedetto F, Paggiaro P, et al. A randomized controlled trial on office spirometry in asthma and COPD in standard general practice: data from spirometry in Asthma and COPD: a comparative evaluation Italian study. Chest 2006;129(4):844-52. http://dx.doi.org/10.1378/chest.129.4.844

17. Walters JA, Hansen EC, Walters EH, Wood-Baker R. Under-diagnosis of chronic obstructive pulmonary disease: a qualitative study in primary care. Respir Med 2008;102(5):738-43. http://dx.doi.org/10.1016/j.rmed.2007.12.008

18. Lindberg A, Bjerg A, Ronmark E, Larsson LG, Lundback B. Prevalence and underdiagnosis of COPD by disease severity and the attributable fraction of smoking Report from the Obstructive Lung Disease in Northern Sweden Studies. Respir Med 2006;100(2):264-72. http://dx.doi.org/10.1016/ j.rmed.2005.04.029

19. Standardization of Spirometry, 1994 Update. American Thoracic Society. Am J Respir Crit Care Med 1995;152(3):1107-36

20. Bateman ED, Hurd SS, Barnes PJ, et al. Global strategy for asthma management and prevention: GINA executive summary. Eur Respir J 2008;31(1):143-78. http://dx.doi.org/10.1183/09031936.00138707

21. Karachaliou F, Kostikas K, Pastaka C, Bagiatis V, Gourgoulianis KI. Prevalence of sleep-related symptoms in a primary care population - their relation to asthma and COPD. Prim Care Resp J 2007; 16(4):222-8. http://dx.doi.org/10.3132/ pcrj.2007.00045

22. Shahab L, Jarvis MJ, Britton J, West R. Prevalence, diagnosis and relation to tobacco dependence of chronic obstructive pulmonary disease in a nationally representative population sample. Thorax 2006;61(12):1043-7. http://dx.doi.org/10.1136/thx.2006.064410

23. Bednarek M, Maciejewski J, Wozniak M, Kuca P, Zielinski J. Prevalence, severity and underdiagnosis of COPD in the primary care setting. Thorax 
2008;63(5):402-07. http://dx.doi.org/10.1136/thx.2007.085456

24. Vandevoorde J, Verbanck S, Gijssels L, et al. Early detection of COPD: a case finding study in general practice. Respir Med 2007;101(3):525-30. http://dx.doi.org/10.1016/j.rmed.2006.06.027

25. Minas M, Dimitropoulos K, Pastaka C, Papadopoulos D, Markoulis N, Gourgoulianis KI. Global initiative for chronic obstructive lung disease for chronic obstructive pulmonary disease: GOLD opportunity for lung disorders. Prev Med 2005;40(3):274-7. http://dx.doi.org/10.1016/j.ypmed.2004.06.010

26. Tzovaras NZ, Kouloumenta VN, Gourgoulianis KI. The economic impact of late detection of COPD in general practice. Chest 2005;127(1):412; author reply -3.

27. Buffels J, Degryse J, Heyrman J, Decramer M. Office spirometry significantly improves early detection of COPD in general practice: the DIDASCO Study. Chest 2004;125(4):1394-9. http://dx.doi.org/10.1378/chest.125.4.1394

28. Miravitlles M, de la Roza C, Naberan K, Lamban M, Gobartt E, Martin A. Use of spirometry and patterns of prescribing in COPD in primary care. Respir Med 2007;101(8):1753-60. http://dx.doi.org/10.1016/j.rmed.2007.02.019

29. Kotz D, Nelemans $P$, van Schayck $C P$, Wesseling GJ. External validation of a COPD diagnostic questionnaire. Eur Respir J 2008;31(2):298-303. http://dx.doi.org/10.1183/09031936.00074307

30. Walters JA, Hansen EC, Johns DP, Blizzard EL, Walters EH, Wood-Baker R. A mixed methods study to compare models of spirometry delivery in primary care for patients at risk of COPD. Thorax 2008;63(5):408-14. http://dx.doi.org/10.1136/thx.2007.082859

31. Enright P. Provide GPs with spirometry, not spirometers. Thorax 2008;63(5):387-8. http://dx.doi.org/10.1136/thx.2007.092916

32. Hassett R, Meade K, Partridge MR. Enhancing the accuracy of respiratory diagnoses in primary care: a report on the establishment of a Community Respiratory Assessment Unit. Prim Care Resp J 2006;15(6):354-61. http://dx.doi.org/10.1016/j.pcrj.2006.10.003

33. Levy ML, Quanjer PH, Booker R, Cooper BG, Holmes S, Small I. Diagnostic spirometry in primary care: Proposed standards for general practice compliant with American Thoracic Society and European Respiratory Society recommendations: a General Practice Airways Group (GPIAG)' document, in association with the Association for Respiratory Technology \& Physiology $(\text { ARTP) })^{2}$ and Education for Health ${ }^{3}$ 'www.gpiag.org "www.artp.org ${ }^{3}$ www.educationforhealth.org.uk. Prim Care Resp \& 2009;18(3):130-47. http://dx.doi.org/10.4104/pcrj.2009.00054

34. van Schayck CP, Levy ML, Stephenson P, Sheikh A. The IPCRG Guidelines: developing guidelines for managing chronic respiratory diseases in primary care. Prim Care Resp J 2006;15(1):1-4. http://dx.doi.org/10.1016/ j.pcrj.2005.12.003

35. Qaseem A, Snow V, Shekelle P, et al. Diagnosis and management of stable chronic obstructive pulmonary disease: a clinical practice guideline from the American College of Physicians. Ann Intern Med 2007;147(9):633-8.

36. de Marco R, Accordini S, Cerveri I, et al. An international survey of chronic obstructive pulmonary disease in young adults according to GOLD stages. Thorax 2004;59(2):120-5. http://dx.doi.org/10.1136/thorax.2003.011163

37. Parkes G, Greenhalgh T, Griffin M, Dent R. Effect on smoking quit rate of telling patients their lung age: the Step2quit randomised controlled trial. BMJ 2008;336(7644):598-600. http://dx.doi.org/10.1136/bmj.39503.582396.25

38. Decramer M, Celli B, Kesten S, Lystig T, Mehra S, Tashkin DP. Effect of tiotropium on outcomes in patients with moderate chronic obstructive pulmonary disease (UPLIFT): a prespecified subgroup analysis of a randomised controlled trial. Lancet 2009;374(9696):1171-8. http://dx.doi.org/ 10.1016/S0140-6736(09)61298-8

39. Svanes C, Sunyer J, Plana E, et al. Early life origins of chronic obstructive pulmonary disease. Thorax 2010;65(1):14-20. Epub 2009 Sep 2. http://dx.doi.org/10.1136/thx.2008.112136

40. Bush A. COPD: a pediatric disease. COPD 2008;5(1):53-67. http://dx.doi.org/10.1080/15412550701815965

41. Sichletidis LT, Chloros D, Tsiotsios I, et al. High prevalence of smoking in Northern Greece. Prim Care Resp J 2006;15(2):92-7. http://dx.doi.org/ 10.1016/j.pcrj.2006.01.004

42. Yin $\mathrm{P}$, Jiang $\mathrm{CQ}$, Cheng $\mathrm{KK}$, et al. Passive smoking exposure and risk of COPD among adults in China: the Guangzhou Biobank Cohort Study. Lancet 2007;370(9589):751-7. http://dx.doi.org/10.1016/S0140-6736(07)61378-6

43. Mannino DM, Buist AS. Global burden of COPD: risk factors, prevalence, and future trends. Lancet 2007;370(9589):765-73. http://dx.doi.org/ 10.1016/S0140-6736(07)61380-4

44. Lamprecht B, Schirnhofer L, Kaiser B, Buist S, Studnicka M. Non-reversible airway obstruction in never smokers: results from the Austrian BOLD study. Respir Med 2008;102(12):1833-8. http://dx.doi.org/10.1016/j.rmed. 2008.07.007

45. Lung function testing: selection of reference values and interpretative strategies. American Thoracic Society. Am Rev Respir Dis 1991;144(5):1202-18.

46. Pellegrino R, Viegi G, Brusasco $V$, et al. Interpretative strategies for lung function tests. Eur Respir J 2005;26(5):948-68. http://dx.doi.org/ 10.1183/09031936.05.00035205

47. Lundback B, Gulsvik A, Albers M, et al. Epidemiological aspects and early detection of chronic obstructive airway diseases in the elderly. Eur Respir $J$ 2003;40:Suppl, 3s-9s. http://dx.doi.org/10.1183/09031936.03.00403103

48. Mannino DM, Sonia Buist A, Vollmer WM. Chronic obstructive pulmonary disease in the older adult: what defines abnormal lung function? Thorax 2007;62(3):237-41. http://dx.doi.org/10.1136/thx.2006.068379

\section{Available online at http://www.thepcrj.org}




\section{Appendix 1. Study questionnaire}

No...... Name Male/Female

Age. Occupation.

Height. Weight

BMI

Did you have a respiratory infection during the last 4 weeks?

Did you receive any antibiotics during the last 4 weeks?

Do you smoke or have you previously smoked?

\begin{tabular}{|c|c|}
\hline If you smoke NOW & If you smoked IN THE PAST \\
\hline What is your starting age? ................... & 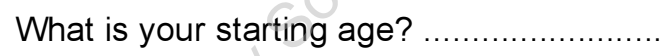 \\
\hline How many cigarettes/day? . & What is the age you stopped smoking? .... \\
\hline PYS .... & $\begin{array}{l}\text { How many cigarettes/day did you smoke? } \\
\text { PYS }\end{array}$ \\
\hline
\end{tabular}

At your occupation, do you have exposure to noxious particles or gases?

What kind of heating and cooking devices do you use at home?

At your childhood, do you remember to have often respiratory infections?

Do you have a previous history/diagnosis of COPD?

Do you use any inhaler medications?

If yes, what and for what reason.

Do you have cough?

Do you produce sputum/phlegm?

Do you have wheezing?

Do you have dyspnea/chest tightness? 